\title{
ANDREMEYERITE, A NEW BARIUM IRON SILICATE, FROM NYIRAGONGO, ZAIRE
}

\author{
Th. G. Sahama, JaAkko Sitvola and Pentti Rehtijärvi
}

\begin{abstract}
Sahama, Th. G., Sirvola, JaAkko and Rehtijärvi, Pentti 1973: Andremeyerite, a new barium iron silicate, from Nyiragongo, Zaire. Bull. Geol. Soc. Finland 45, $1-8$.
\end{abstract}

This paper presents a new silicate, andremeyerite, from the Nyiragongo volcano in Zaire. The mineral occurs in the vesicles of a melilite-leuciteneph linite block carried up by later nephelinite lava. The constituents of the vesicles are briefly described.

Andremeyerite is monoclinic, space group $P 2_{1} / c$. Unit cell: $a_{0}=7.464 A$, $b_{o}=13.794 A, c_{o}=7.093 A, \beta=118^{\circ} 15^{\prime}$. Indexed powder pattern given. Crystals prismatic with (100), (120), (010), (011) simulating tetragonal shape. Perfect cleavage on (100) and (010). Multiple twinning on (100). Density 4.15. Vickers indentation microhardness $440 \mathrm{~kg} / \mathrm{mm}^{2}$. Strong dispersion. Optical orientation: $\gamma \| b, c \Lambda \alpha$ varying from $2^{\circ}$ (for $670 m \mu$ ) to $61^{\circ}$ (for $470 m \mu$ ). Position of the optic axes given in stereographic projection. Optic sign + . Overall color pale emerald green. Pleochroism in daylight: $\alpha=$ slightly bluish green, $\beta \sim \gamma=$ colorless with a faint brownish tint. Refractive indices in sodium light: $\alpha \sim \beta=1.740, \gamma=1.760$. Idealized chemical formula $\mathrm{BaFe}_{2} \mathrm{Si}_{2} \mathrm{O}_{7}$ with $Z=4$. The iron is probably mainly in the ferrous state. The mineral starts decomposing at ca. $800^{\circ} \mathrm{C}$.

Th. G. Sabama and Pentti Rebtijärvi, Dept. of Geology, University of Helsinki, 00170 Helsinki 17, Finland.

Jaakeo Siivola, The Geological Survey of Finland, 02150 Otaniemi, Finland.

\section{Introduction}

A number of rounded blocks are found on the southern rim of the Nyiragongo volcano (Virunga volcanic field in eastern Zaire, formerly the Belgian Congo) which range in size up to that of a man's head. In bulk chemical com- position these blocks do not differ much from that of the embedding wnepheline aggregate lava», the same type of lava which constitutes the molten rock material of the present-day lava lake. The blocks consist of melilite-leucite-nephelinite. Some of the constituents and the textural features reveal, however, that, after the 
initial crystallization, these blocks were subjected to thermal metamorphism. They evidently originate from earlier products of extrusion and were carried up by later outpourings of the ancient lava lake.

In 1958 and 1959 a number of specimens of these blocks were collected by the late Mr André Meyer, of the Geological Survey of the Belgian Congo, and by one of us (Th. G. S.). The vesicles of one of the specimens numbered $V S$. 219 was found to contain some irregular grains and euhedral crystals of a mineral which could not be identified. For the most part the single grains of the mineral do not measure more than $0.1 \mathrm{~mm}$ in diameter. The prismatic crystals only rarely reach a length of $0.2 \mathrm{~mm}$. When subjected to a closer study, this mineral was found to represent a new barium iron silicate. In honor of Mr. Meyer, who contributed much to the knowledge of Mt. Nyiragongo, this mineral is here named andremeyerite. The name has been approved by the Commission on New Minerals and Mineral Names of the International Mineralogical Association. This paper presents the properties of andremeyerite.

\section{Associated minerals}

The following minerals were found associated with andremeyerite in the vesicles of specimen VS. 219:

Nepheline. Clear, often stout prims. Average composition $30 \frac{1}{2} \pm 1$ mol. $\% \mathrm{KAlSiO}_{4}$.

Leucite. Usually turbid, more or less rounded twinned crystals. $a_{0}=13.065 A, c_{0}=13.784 A$ (both $\pm 0.005 A$ ).

Clinopyroxene. Well-developed brownish green crystals, often flat parallel to (100). Common twinning.

Sub-calcium olivine. Crystal faces invariably (102), (011) and (001). The faces are never smooth but rough without regular growth hillocks (Fig. 1). The composition and properties of the mineral are summarized in Table 1.

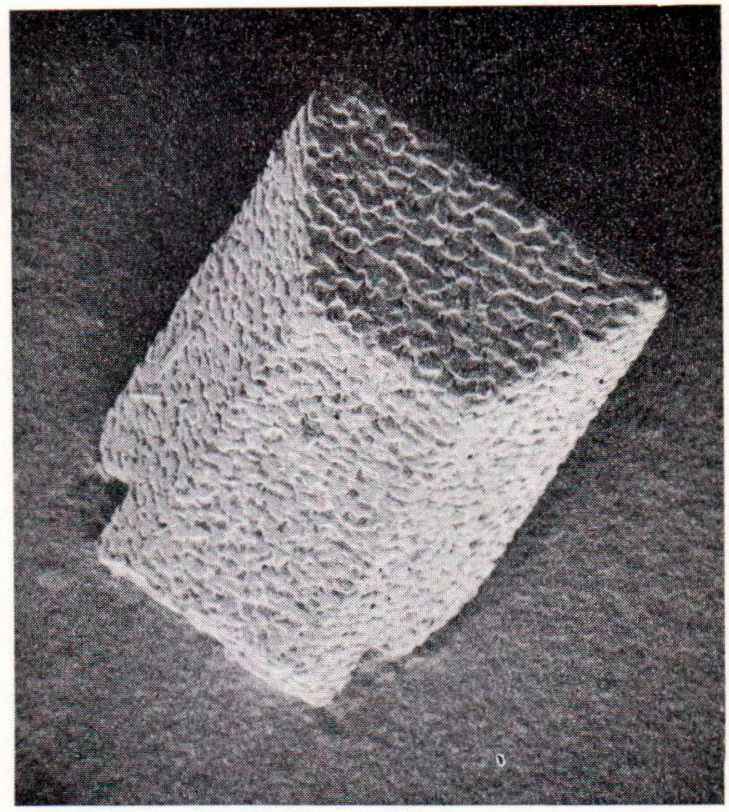

Fig. 1. Crystal habit of sub-calcium olivine. Scanning electron micrograph, $850 \times$.

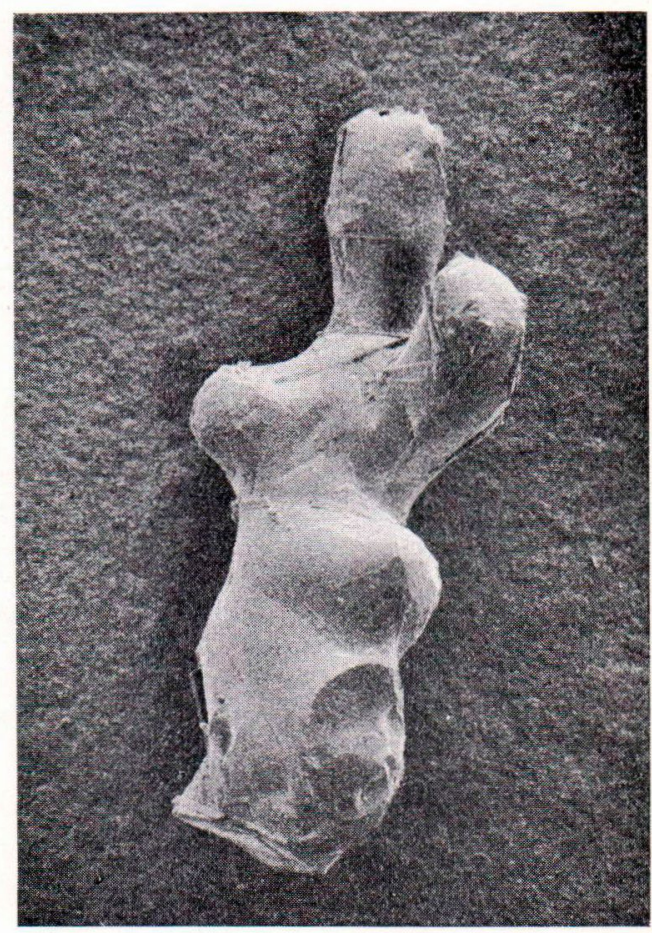

Fig. 2. Rounded troilite »droplet». Scanning electron micrograph, $200 \times$. 
TABLE 1.

Chemical composition and physical data for the sub-calcium olivine of specimen VS. 219, Nyiragongo.

Wet chemical analysis by Pentti Ojanperä.

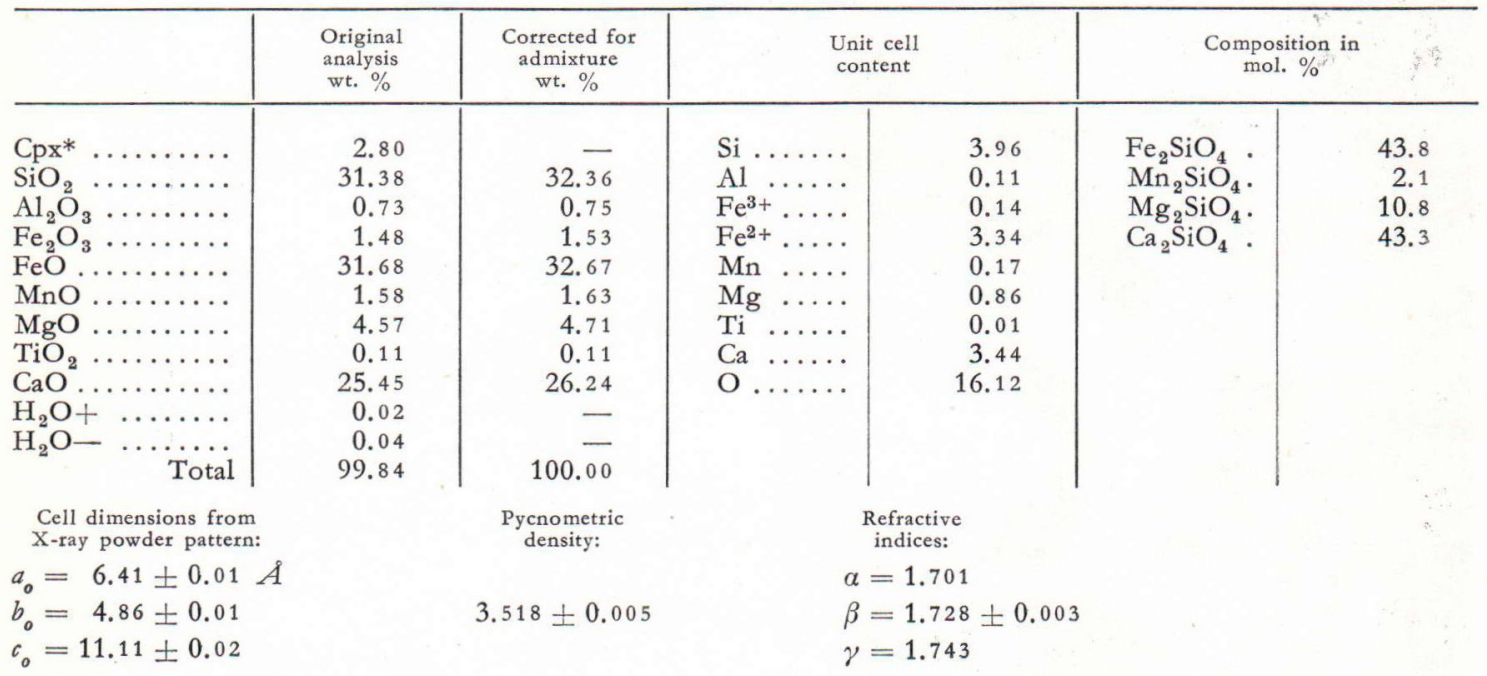

* Clinopyroxene residue left behind when dissolving the olivine material in hydrochloric acid.

Melilite. Slightly brownish red prims. Crystal faces rough like those of the sub-calcium olivine. Apatite in fine needles.

Magnetite. Shiny crystals with (111) and (110). Götzenite. Rare needles identified by a $b$-axis rotation photograph.

Troilite. Opaque drop-like single crystals (Fig. 2) identified by their optical properties in reflected light and by an X-ray powder pattern. Nonmagnetic.

Green glass. Chemical composition summarized in Table 2. Refractive index $n=1.598 \pm$.

TABLE 2.

Chemical composition of the green glass of specimen VS. 219, Nyiragongo.

Microprobe analysis by Jaakko Siivola.

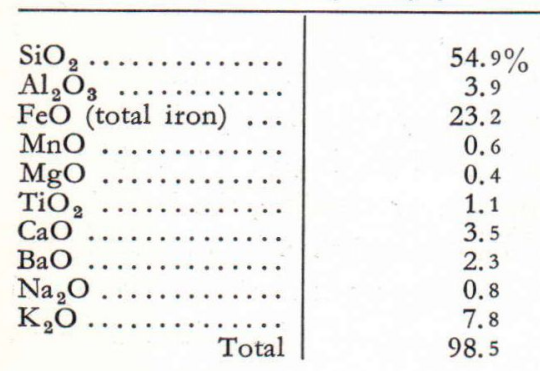

\section{Crystal morphology}

The andremeyerite grains occur largely embedded in or in contact with the green glass. When euhedral, the habit is prismatic and the end faces simulate tetragonal symmetry. The Xray data to be presented below reveal that the mineral is monoclinic. Fig. 3, A and B, illustrates the actual shape of the crystals observable under a scanning electron microscope. The crystals are too small for accurate optical goniometry. Therefore, the angles between the crystal faces and edges were roughly measured under a petrographic microscope. Fig. 4, which illustrates the ideal crystal shape of the mineral, was drawn on the basis of the unit cell dimensions and the indices were assigned to suit the angles between the faces found. The setting (monoclinic second setting of the International Tables for X-ray Crystallography) conforms with the $\mathrm{X}$-ray precession photographs.

The mineral exhibits perfect prismatic cleavages on (100) and on (010). This fact greatly facilitates the adjusting of the crystal in a pre- 


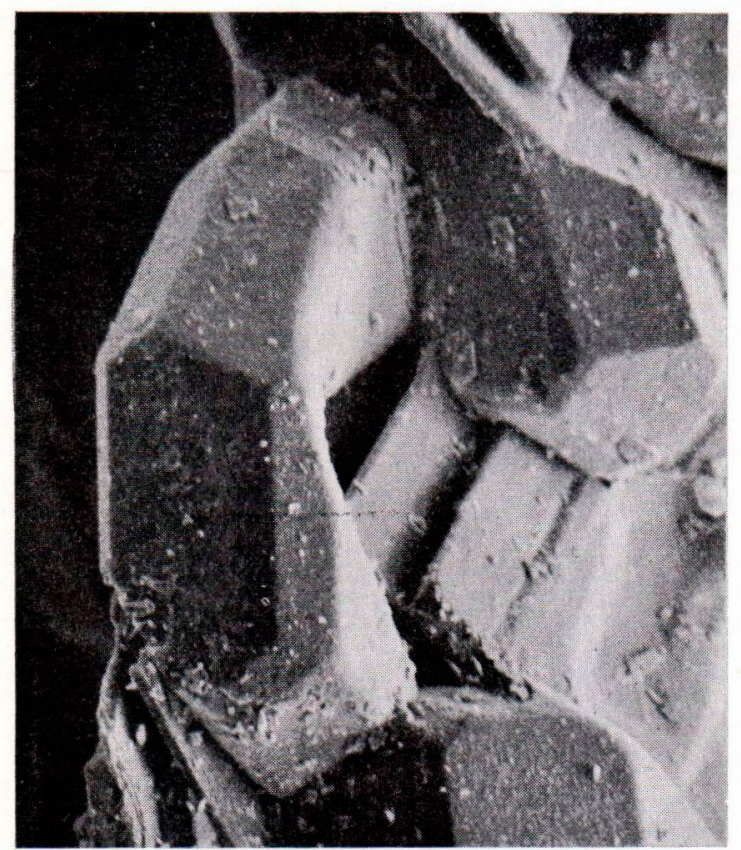

A

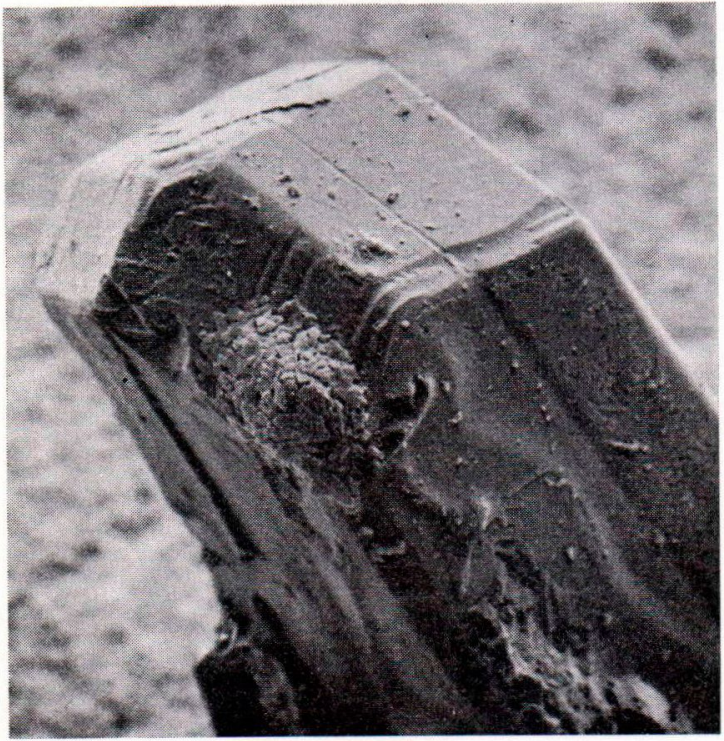

B

Fig. 3. Scanning electron micrographs illustrating the actual shape of the andremeyerite crystals. A. $1000 \times$. B. $700 \times$.

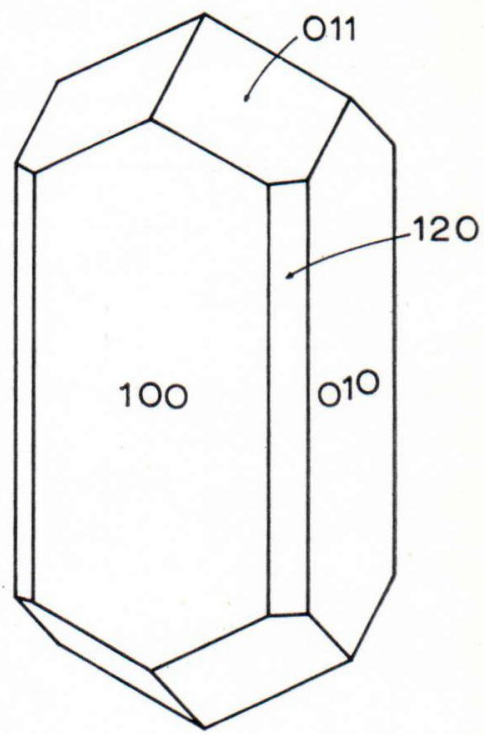

Fig. 4. Crystal habit of andremeyerite.

cession camera and its mounting for optical study under the microscope.

Under a polarizing microscope the crystals mounted on (010) display a multiple twinning on (100).

\section{Crystal geometry}

Andremeyerite was studied by the single crystal precession method and by X-ray powder pattern. A series of precession photographs revealed monoclinic symmetry with systematic extinctions conformable with space group $P 2_{1} / c$. The powder pattern is reproduced in Table 3 . Due to the small amount of material available for recording the powder pattern, some of the weak lines could not be measured accurately. In addition, the monoclinic symmetry with its specific cell dimensions made the indexing of a few lines not equivocal. Where ever possible, the indexing of the powder lines was checked by observing the intensities of the reflections in the single crystal photographs. The unit cell dimensions deduced 
TABle 3.

X-ray powder pattern of andremeyerite. Philips wide angle diffractometer, internal silicon standard.

\begin{tabular}{|c|c|c|c|}
\hline hk1 & I & $\mathrm{d}_{\text {meas. }}$ & $\mathrm{d}_{\text {calc. }}$ \\
\hline 021 & & & \\
\hline$\left\{\begin{array}{l}12 \overline{1} \\
\text {. }\end{array}\right.$ & 40 & 4.63 & 4.63 \\
\hline $10 \overline{2}$ & 15 & 3.55 & 3.55 \\
\hline 040 & 15 & 3.45 & 3.45 \\
\hline 200 & 60 & 3.288 & 3.289 \\
\hline 210 & 20 & 3.198 & 3.199 \\
\hline $002 *$ & & & 3.126 \\
\hline $20 \overline{2}$ & 80 & 3.122 & 3.118 \\
\hline 140 & 100 & 3.055 & 3.054 \\
\hline 041 & 20 & 3.019 & 3.019 \\
\hline 131 & 15 & 2.902 & 2.899 \\
\hline $13 \overline{2}$ & 40 & 2.811 & 2.808 \\
\hline 141 & 15 & 2.536 & 2.534 \\
\hline $24 \overline{1}$ & & & 2.531 \\
\hline 051 & 15 & 2.525 & 2.524 \\
\hline $15 \overline{1}$ & & & 2.523 \\
\hline $14 \overline{2}$ & 55 & 2.472 & 2.472 \\
\hline 221 & 15 & 2.326 & 2.325 \\
\hline 060 & 15 & 2.300 & 2.299 \\
\hline $12 \overline{3}$ & 10 & 2.205 & 2.206 \\
\hline $15 \overline{2}$ & & & 2.178 \\
\hline 231 & 20 & $2.175 b$ & 2.175 \\
\hline 160 & & & 2.170 \\
\hline $13 \overline{3}$ & 15 & 2.075 & 2.077 \\
\hline $23 \overline{3}$ & & & 2.075 \\
\hline 023 & 10 & 1.997 & 1.995 \\
\hline 142 & 15 & 1.978 & 1.978 \\
\hline 161 & 10 & 1.959 & 1.958 \\
\hline $26 \overline{1}$ & 10 & & 1.956 \\
\hline 062 & & & 1.852 \\
\hline 212 & 15 & $1.853 \mathrm{~b}$ & 1.851 \\
\hline 340 & & & 1.850 \\
\hline 080 & 15 & 1.724 & 1.724 \\
\hline 081 & 15 & 1.662 & 1.662 \\
\hline 082 & 15 & 1.509 & 1.510 \\
\hline
\end{tabular}

* Line coincides with $S i$ 111. The $2 \theta$-value was measured from a chart recorded without a silicon standard and corrected on the basis of lines 200 and 140 .

$\mathrm{b}=$ broad.

from the precession photographs and refined by the powder pattern are:

$$
\begin{aligned}
a_{o} & =7.464 \pm 0.008 A \\
b_{0} & =13.794 \pm 0.005 \\
c_{0} & =7.093 \pm 0.005 \\
\beta & =118^{\circ} 15^{\prime} \pm 10^{\prime} \\
\text { Volume } & =643.3 \pm 1.0 A^{3}
\end{aligned}
$$

These unit cell dimensions and, in addition, the multiple twinning on (100) make the $b$-axis precession photographs simulate a reciprocal cell with orthorhombic axes. The systematic extinctions which are not affected by the twinning disclose true monoclinic symmetry. The monoclinic symmetry is further evidenced by the optical dispersion of the mineral to be presented below.

\section{Chemistry}

The amount of andremeyerite which could be obtained from specimen VS. 219 did not allow a wet chemical analysis. The result of the microprobe analysis made by one of us (J. S.) is reproduced in Table 4 . This table also gives the unit cell content based on the cell volume and density found.

A qualitative microprobe test did not reveal the presence of any additional elements with an atomic number higher than that of sodium. An optical spectroscopic test made on an impure material containing some $4 \%$ andremeyerite indicated the absence of lithium, beryllium and boron. Accordingly, these three elements can be present in andemeyerite but, if so, then only in trace amounts. Carbon and fluorine could not be tested. If carbon were to be contained in the andremeyerite structure, then calcite would be expected to occur in the vesicles. No calcite could, however, be detected. If fluorine were to represent an essential anion of the andremeyerite structure, then some content of chlorine should have revealed itself in the microprobe tests made on the mineral. A more significant water content should have made itself apparent not only during the bombardement of the thin section with the electron beam in the microprobe but also during the heating at the microscope heating stage. No effect of any possible water content could be detected.

It is concluded that no elements additional to those mentioned in Table 4 are contained in the andremeyerite structure except possibly in trace 
TABLE 4.

Chemical composition of andremeyrite from Nyiragongo, Zaire.

Microprobe analysis by Jaakko Siivola.

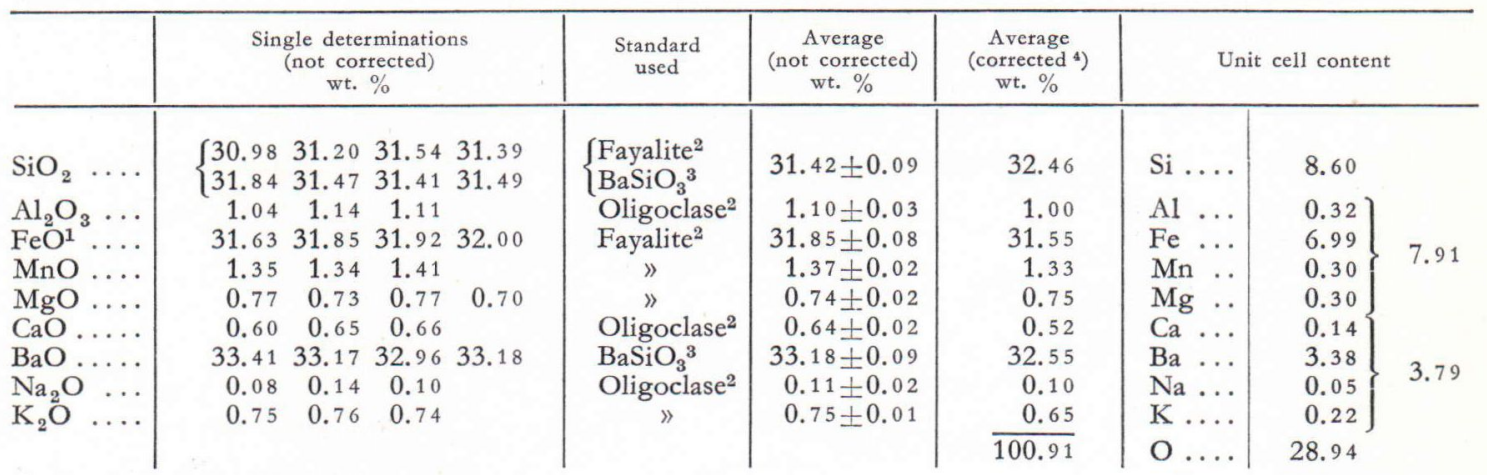

$\mathrm{TiO}_{2}$ not detected.

1 total iron.

2 analyzed natural mineral.

3 synthetic glass.

4 Corrected for background, absorption and fluorescence.

or minor amounts. The degree of oxidation of iron could not be determined. The greenish color of the mineral suggests that the iron is mainly in the ferrous state.

The unit cell content summarized in Table 4 corresponds reasonably well to the idealized formula $\mathrm{BaFe}_{2} \mathrm{Si}_{2} \mathrm{O}_{7}$ with $Z=4$ except that the mineral contains a non-stoichiometric excess of some 0.6 atoms Si per unit cell. The thin section reveals a close connection between the andremeyerite crystals and the green glass. This fact suggests that the crystallization of andremeyerite occurred at the expense of the glass deposited in the vesicles and that andremeyerite represents one of the last crystallizations among the vesicle constituents. The glass is considerably richer in silica than is andremeyerite. It does not seem unreasonable to assume that the excess silica found in the andremeyerite structure originates from the glass and was trapped in the andremeyerite structure during the crystallization process. The ideal formula proposed for andremeyerite conforms with the requirements of the space group found.

Due to the scarcity of the andremeyerite material no DTA run could be made. Instead, a few grains of the mineral were mounted on a sapphire glass plate and placed on a microscope heating stage. The temperature was slowly raised to $1000^{\circ} \mathrm{C}$ and the grains were observed under crossed nicols. It was found that at about $800^{\circ} \mathrm{C}$ the mineral started to become turbid. At about $900^{\circ} \mathrm{C}$ the grains were virtually non-transparent. After the run the material was studied under an ordinary petrographic microscope. The turbid grains had turned brown, apparently due to the oxidation of iron. The decomposed crystals had developed a corona of colorless crystalline, birefringent sublimate on the glass plate. The refractive indices of this sublimate are well above 1640 . Accordingly, the sublimate is not silica in any modification but possibly represents a barium silicate, the accurate identification of which is difficult.

\section{Density and hardness}

The material available was too scanty for a density determination with a pycnometer or Berman balance. Therefore, crushed material containing some andremeyerite grains were cen- 
trifuged in Clerici solutions of known densities. After each centrifuging the tube containing the suspension was studied under a binocular microscope to see whether the pure andremeyerite grains were lying at the bottom of the tube or floating on the surface of the liquid. In this way a density of $d=4.15$ was deduced for the mineral. Because the grains were for the most part slightly contamined, the uncertainty of \pm 0.02 must be attributed to the density value adopted.

The density of the theoretical $\mathrm{BaFe}_{2} \mathrm{Si}_{2} \mathrm{O}_{7}$ with the unit cell volume of andremeyerite is calculated to $d=4.31$ and that of $(\mathrm{Ba}, \mathrm{K}, \mathrm{Ca}, \mathrm{Na})$ (Fe, $\mathrm{Al}, \mathrm{Mn}, \mathrm{Mg})_{2} \mathrm{Si}_{2} \mathrm{O}_{7}$ to $d=4.14$.

The Vickers micro-indentation hardness was determined on a polished section by Mr. Esko Hänninen, of the Outokumpu Company, Tapiola, Finland. The resulting value was $440 \mathrm{~kg} /$ $m m^{2}$, which corresponds to roughly $5 \frac{1}{2}$ in Moh's scale.

\section{Optical properties}

Due to the smallness of the andremeyerite crystals in the vesicles, the mineral can hardly be distinguished by the unaided eye in a hand specimen. Under a binocular microscope, however, the overall emerald green color makes it easily detectable both in the specimen itself and in the crushed rock material. In transmitted light the mineral exhibits a marked dichroism: very pale brownish, almost colorless when viewed along the $c$-axis and green with a slight bluish tint when viewed perpendicular to the $c$-axis.

In order to determine the optical properties, andremeyerite crystals or cleavage pieces were placed on a slide and turned to rest on (100) or (010), respectively, under a binocular microscope. The slide was then transferred to a polarizing microscope. For the universal stage work the crystals were embedded in cement with $n_{N a}=$ 1.665 (Monsanto Aroclor cement No. 4465). The use of this cement facilitates the transparency of

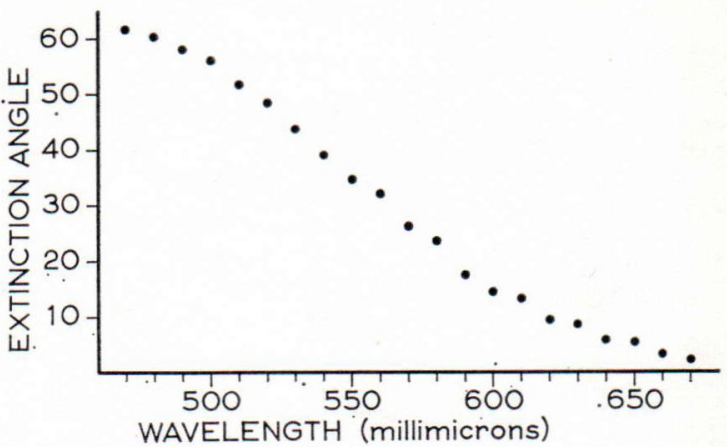

Fig. 5. Dispersion of the optical extinction direction on (010). Extinction angle $c \Lambda \alpha$ plotted against the wavelength of the monochromatic light used.

the highly refractive andremeyerite crystals because it has a refractive index considerably higher than that of Canada balsam. This fact was found to be of importance especially when working at the far red and blue ends of the visible spectrum. Due to the very strong dispersion displayed, the optical study of the mineral had to be carried out in monochromatic light extending in wavelength from $470 m \mu$ to $670 m \mu$.

No extinction was found between crossed nicols in daylight. On (100) the non-extinction is caused by the multiple twinning and on (010) by the dispersion. The variation of the extinction direction on (010) with the wavelength of the light used is illustrated in Fig. 5. The following optical orientation was deduced:

$$
\begin{gathered}
\gamma \| b \text { (for all colors) } \\
c \Lambda \alpha=2^{\circ}(670 m \mu) \text { to } 61^{\circ}(470 m \mu) .
\end{gathered}
$$

The dispersion of the optic axial angle, as determined with the universal stage, is illustrated by the stereographic projection of Fig. 6. Below $490 m \mu$ the mineral is almost uniaxial. With increasing wavelength the optic axial angle increases, reaches a maximum of $2 \mathrm{~V}=\mathrm{ca} .40^{\circ}$ at about $540 m \mu$ and decreases again. At ca. 580$585 m \mu$ the mineral becomes virtually uniaxial. Towards longer wavelengths the optic axial angle opens up and reaches a value of some $80^{\circ}$ at 


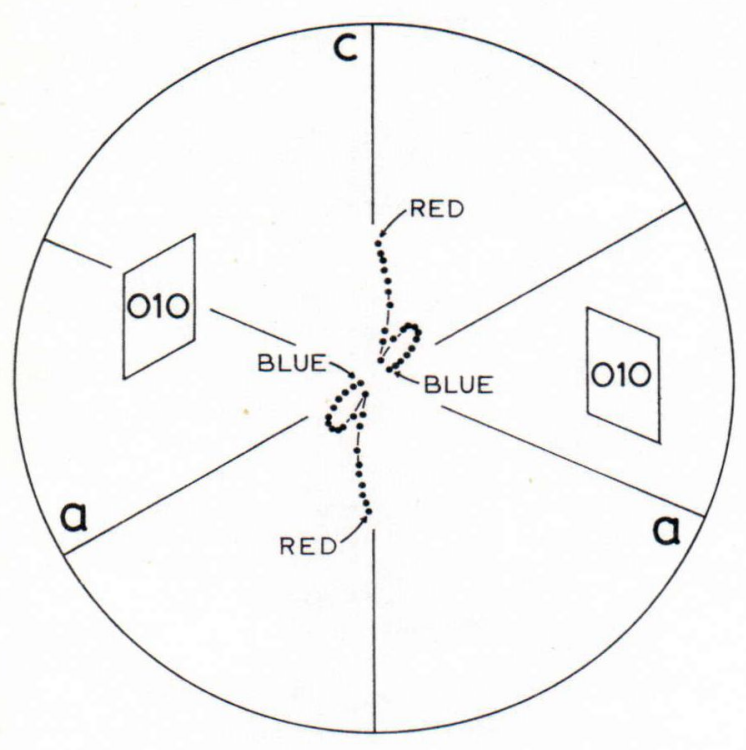

Fig. 6. Position of the optic axes in monochromatic light. Stereographic projection.

Red: $\lambda=670 m \mu$. Blue: $\lambda=470 m \mu$.

$670 m \mu$. Accordingly, the mineral remains optically positive for the wavelength range studied. Because of the pseudo-orthorhombic appearance of the $b$-axis precession photographs, caused by twinning, it is not possible to tell which one of the two directions of the $a$-axes marked in Fig. 6 corresponds to the variation of the optic axes measured on either of the two twinned individuals.

The refractive indices measured by the immersion method in sodium light were found to be $\alpha \backsim \beta=1.740 \pm 0.005, \gamma=1.760 \pm 0.005$. Pleochroism in daylight: $\alpha=$ slightly bluish green, $\beta \sim \gamma=$ colorless with a faint brownish tint. Absorption: $\alpha>\beta \sim \gamma$.

\section{Reference material}

Andremeyerite has been found in only one specimen. The amount of material left over from this study measures not more than a few milligrams partly contained in an impure concentrate of heavy vesicle minerals and partly in a few pieces of the specimen with some vesicles. This material is stored at the Dept. of Geology, University of Helsinki, Finland.

Manuscript received, February 28, 1972. 